\title{
Strategi Promosi dan Store Interior Terhadap Daya Beli Konsumen Pada Industri Ritel (Studi Kasus Indomaret Johor)
}

\author{
Ronda Deli Sianturi, Anda Yanny* \\ Prodi Manajemen Retail, Fakultas Ekonomi dan Bisnis, Universitas Budi Darma \\ Email: Rondadeli398@gmail.com, Andayanny36@gmail.com
}

\begin{abstract}
Abstrak-Untuk meningkatkan minat beli pelanggan terhadap suatu produk, perusahaan harus secara bersama-sama memaksimalkan secara tepat apa yang dibutuhkan pelanggan. Promosi merupakan faktor yang penting untuk meningkatkan minat beli pelanggan.Store Interior juga merupakan faktor penting untuk meningkatkan minat beli pelanggan.Saat ini industri ritel seperti Indomaret Johor mengalami penurunan jumlah konsumen. Tujuan dari penelitian ini adalah untuk mengetahui pengaruh dari promosi dan store interior terhadap minat beli pelanggan Indomaret. Tipe penelitian yang digunakan yaitu kuantitatif. Sumber data diperoleh melalui penelitian lapangan dan penelitian kepustakaan. Jumlah sampel 25 orang diambil dari pelanggan Indomaret Johor. Penelitian ini menggunakan SPSS V.20 dan regresilinear berganda. Teknik analisis data yang digunakan dalam penelitian ini adalah analisis regresi linear berganda, untuk menganalisis dampak promosi dan store interior terhadap minat beli pelanggan. Hasil analisis menunjukkan bahwa variabel promosi dan variabel store interior mempunyai pengaruh secara signifikan terhadap minat beli pelanggan Indomaret Johor. Hal ini menunjukkan bahwa promosi dan store interior sebagai manfaat bagi pelanggan yang akan mempengaruhi minat beli pelanggan untukmelakukan pembelian. Penelitian ini memberikan manfaat bagi perusahaanagar dapat memprioritaskan dalam mengelola promosi dan store interior denganlebih efektif, karena pelanggan lebih mengutamakan promosi dan store interior dalam melakukan pembelian.
\end{abstract}

Kata Kunci: Promosi; Store Interior; Minat Beli

\begin{abstract}
To increase customer interest in the purchase of a product, companies must jointly maximize appropriately what is needed customer. Promotion is important factor to increase the interest of the customer purchase. Store Interior is also an important factor to increase the interest of customer purchase. Currently the retail industry such as Indomaret Johor has decreased the number of consumers. The purpose of this study was to determine the effect of promotion and interior toward customer purchase interest Indomaret Johor. This type of research is quantitative. Sources of data obtained through field research and library research. The number of samples taken from 25 people Indomaret customers Johor. This study used SPSS V.20 and multiple linear regression. Data analysis techniques used in this research is multiple linear regression analysisto analyze the impact of promotions and store interiors to the interest of customer's purchase. The analysis showed that the variables of sale and store interior have a significant influence on interest of the customer purchase Indomaret Johor. This show that promotion and store interior as benefit for customers that will affect the buying interest of customers to maka a purchase.This research provides benefits for compaies in order to prioritize in managing the promotion and store interior more effectively because customers prefer promotions and store interior to make a purchase.
\end{abstract}

Keywords: Promotion; Store Interior; Purchase Interests

\section{PENDAHULUAN}

Perkembangan usaha retail di Indonesia berkembang pesat, dapat kita lihat semakin bertumbuh nya gerai gerai retail di kota kota besar, bahkan mulai merambah ke pedesaan. Menurut Eva (2016), data Industri minimarket, supermarket, hypermarket di Indonesia menampilkan persaingan, ekspansi dan pertumbuhan industri ritel modern di Indonesia yang mencakup minimarket, supermarket, Hypermarket dan modern trade di Indonesia sejak 2012-2021. Indonesia memiliki banyak industri ritel seperti mini market, supermarket, hypermarket dan modern trade.Industri ritel lebih diminati oleh pengusaha dan konsumen khususnya mini market. Hal ini terlihat pada menjamurnya industri ritel seperti Indomaret Hampir disetiap wilayah di Indonesia memiliki industri ritel seperti Indomaret .Industri ritel modern segmen minimarket di I1ndonesia tahun 2016 mengalami pertumbuhan sebesar 13,94\%. Laporan Global Retail Development Index menunjukkan peringkat Indonesia posisi kelima dengan nilai penjualan mencapai US \$ 324 miliar. Akan tetapi banyaknya industri ritel tentu akan menjadi persaingan bagi pengusaha ritel. Lubis (2016), menyatakan bahwa pengusaha ritel harus bisa bersaing dengan pengusaha ritel lainnya. Berdasarkan data terjadi persaingan ketat di segmen minimarket seperti Alfamart yang diusung PT Alfaria Trijaya Tbk dengan PT. Indomarco (Indomaret) dan 7- Eleven diusung oleh PT Modern Internasional Tbk (MDRN).

Jaringan minimarket Indomaret akan menjadi jaringan ritel yang paling baik di Indonesia. Untuk bisa bersaing pengusaha ritel harus mengetahui strategi memenangkan hati pelanggan agar dapat bertahan, khususnya Indomaret harus mengetahui strategi untuk mendapatkan minat beli pelanggan yaitu dengan promosi dan store interior. Menurut Kotler (2007), promosi merupakan salah satu kegiatan pemasaran yang penting bagi perusahaan dalam upaya mempertahankan kelangsungan hidup perusahaan serta meningkatkan kualitas penjualan untuk meningkatkan kegiatan pemasaran dalam hal memasarkan barang atau jasa dari perusahaan. Atmosfer setiap toko mempunyai tata letak fisik yang memudahkan atau menyulitkan untuk berputar-putar didalamnya Suatu toko harus membentuk suasana terencana yang sesuai dengan pasar sasarannya dan dapat menarik konsumen untuk membeli di toko tersebut. Indomaret merupakan salah satu dari minimarket di Indonesia yang paling diminati pelanggan. Pertumbuhan tahunan sebesar $20 \%$ menjadikan Indomaret menempati posisi kedua perusahaan ritel yang tumbuh paling pesat di Asia tahun 2013. Berdasarkan fakta lapangan dan penelitian menunjukkan bahwa kesuksesan dalam meningkatkan minat beli pelanggan 
akan ditentukan oleh promosi suatu produk dan store interior. Untuk meningkatkan minat beli pelanggan terhadap suatu produk, perusahaan harus secara bersama- sama memaksimalkan secara tepat apa yang dibutuhkan pelanggan.

Saat ini industri ritel seperti Indomaret Johor. mengalami penurunan jumlah konsumen. Tujuan dari penelitian ini untuk mengetahui variabel dari promosi atau store interior yang memiliki pengaruh terhadap minat beli pelanggan secara individu dan keseluruhan. Hal ini akan menginformasikan variabel yang paling memberikan manfaat bagi pelanggan dalam mempengaruhi minat beli pelanggan untuk melakukan pembelian. Harapan dari pelanggan adalah agar mendapatkan promosi dan store interior yang nyaman lebih dari persepsinya sehingga pelanggan merasa puas. Berdasarkan fakta lapangan dan penelitian menunjukkan bahwa kesuksesan dalam meningkatkan minat beli pelanggan akan ditentukan oleh promosi suatu produk dan store interior. Untuk meningkatkan minat beli pelanggan terhadap suatu produk, perusahaan harus secara bersama- sama memaksimalkan secara tepat apa yang dibutuhkan pelanggan. Saat ini industri ritel seperti Indomaret Johor. Mengalami penurunan jumlah konsumen. Tujuan dari penelitian ini untuk mengetahui variabel dari promosi atau store interior yang memiliki pengaruh terhadap minat beli pelanggan secara individu dan keseluruhan. Hal ini akan menginformasikan variabel yang paling memberikan manfaat bagi pelanggan dalam mempengaruhi minat beli pelanggan untuk melakukan pembelian. Harapan dari pelanggan adalah agar mendapatkan promosi dan store interior yang nyaman lebih dari persepsinya sehingga pelanggan merasa puas. Saat ini industri ritel seperti Indomaret Johor. Mengalami penurunan jumlah konsumen.

Tujuan dari penelitian ini untuk mengetahui variabel dari promosi atau store interior yang memiliki pengaruh terhadap minat beli pelanggan secara individu dan keseluruhan. Hal ini akan menginformasikan variabel yang paling memberikan manfaat bagi pelanggan dalam mempengaruhi minat beli pelanggan untuk melakukan pembelian. Harapan dari pelanggan adalah agar mendapatkan promosi dan store interior yang nyaman lebih dari persepsinya sehingga pelanggan merasa puas.

\section{KAJIAN TEORI}

\subsection{Minat Beli}

Menurut Oliver (2008), minat beli adalah sesuatu diperoleh dari proses belajar dan proses pemikiran yang yang membentuk suatu persepsi. Minat beli ini menciptakan suatu motivasi yang terus terekam dalam benaknya dan menjadi suatu keinginan yang sangat kuat yang pada akhirnya ketika seorang konsumen harus memenuhi kebutuhannya akan mengaktualisasikan apa yang ada didalam benaknya itu. Keller (2007) menyatakan bahwa minat beli konsumen adalah seberapa besar kemungkinan konsumen membeli suatu merek atau seberapa besar kemungkinan konsumen untuk berpindah dari satu merek ke merek lainnya".

\subsection{Promosi}

Swasta \& Irawan (2008), menyatakan bahwa promosi adalah arus informasi atau persuasi satu arah yang dibuat untuk mengarahkan seseorang atau organisasi kepada tindakan yang menciptakan pertukaran dalam pemasaran. Menurut Alma (2007), promosi adalah sejenis komunikasi yang memberi penjelasan yang meyakinkan calon konsumen tentang barang dan jasa. Tjiptono ( 2007), menyatakan bahwa tujuan dari pada perusahaan melakukan promosi adalah menginformasikan mempengaruhi dan membujuk serta mengingatkan pelangggan tentang produk perusahaan dan strategi promosinya. Promosi akan mempercepat penyampaian strategi pemasaran kepada konsumen.Dalam melakukan promosi agar dapat efektif perlu adanya bauran promosi, yaitu kombinasi yang optimal bagi berbagai jenis kegiatan atau pemilihan jenis kegiatan promosi yang paling efektif dalam meningkatkan penjualan.

\subsection{Store Atmosphere}

Menurut Berman \& Evan (2007), Atmosphere refers to the store's physical characteristics that project an image and draw customer. Utami (2006), mengatakan bahwa store atmosphere adalah desain lingkungan melalui komunikasi visual, pencahayaan, warna, musik, dan wangi-wangian untuk merancang respon emosional dan persepsi pelanggan dan untuk mempengaruhi pelanggan dalam membeli barang. Elemen-Elemen Store Atmosphere Menurut Berman \& Evan (2007), elemen- elemen store atmosphere ke dalam 4 elemen, yaitu

\section{METODOLOGI PENELITIAN}

\subsection{Sumber dan Teknik Pengumpulan Data}

Penelitian ini menggunakan bentuk penelitian kuantitatif. Metode penelitian yang dilakukan adalah metode survey. Data yang digunakan adalah data primer. Data primer dalam penelitian ini adalah data yang diperoleh dengan survey lapangan melalui pembagian kuesioner kepada responden.Teknik pengumpulan data ada 2 yaitu studi pustaka, kuesioner.

\subsection{Populasi dan Sampel}

Sekumpulan objek yang akan dijadikan sebagai bahan penelitian dengan ciri mempunyai karakteristik yang sama pada penelitian ini atau populasinya adalah 25 pelanggan Indomaret Johor 


\subsection{Uji Coba Instrumen Penelitian Uji Validitas}

Menurut Ghozali (2007). uji validitas digunakan untuk mengukur sah atau valid tidaknya suatu kuesioner. Suatu kuesioner dikatakan valid jika pertanyaan pada kuesioner mampu untuk mengungkap sesuatu yang akan diukur oleh kuesioner tersebut.

\subsection{Koefisien korelasi ( $\mathbf{R})$ dan determinasi $\left(\mathbf{R}^{2}\right)$}

Koefisien korelasi ( $\mathrm{R})$ dan determinasi $\left(\mathrm{R}^{2}\right)$ berguna untuk mengukur seberapa jauh kemampuan model dalam menerapkan variabel terikat.Langkah selanjutnya mencari koefisien regresi untuk masing-masing variabel bebas yaitu untuk mengetahui variabel bebas mana yang memberikan sumbangan terbesar terhadap variabel tidak bebas.

\subsection{Teknik Analisa Data Regresi Linear Berganda}

Teknik analisis data yang digunakan dalam penelitian ini adalah analisis regresi berganda yang dapat mengetahui seberapa besar pengaruh variabel bebas terhadap variabel terikat, yaitu pengaruh promosi dan store interior terhadap minat beli. Untuk mengetahui hubungan dan pengaruh variabel independent terhadap variabel dependent yang lain, maka digunakan uji regresi. Hubungan antara variabel dependent dengan lebih dari satu variabel independent disebut regresi berganda sebesar 5\%.

\subsection{Kerangka Konseptual}

Model ini terdiri dari dua variabel independen, yaitu Promosi, Store Interior dan variabel dependen adalah Minat Beli Pelanggan

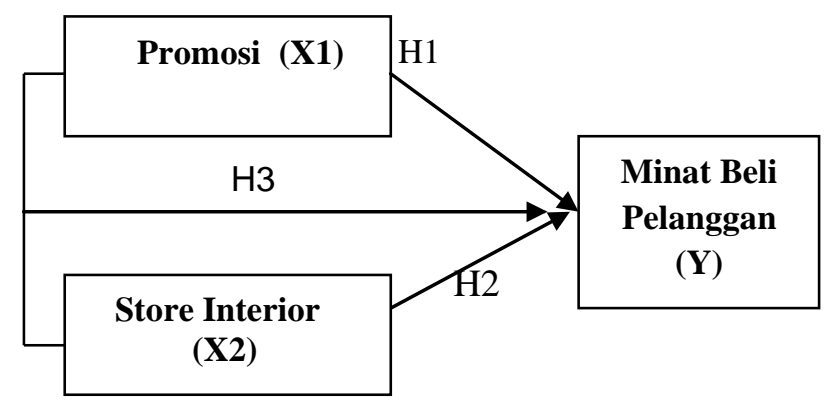

Gambar 1. Kerangka Berfikir

\subsection{Hipotesis Penelitian}

H1. Promosi berpengaruh positif dan signifikan terhadap minat beli pelanggan.

H2. Store Interior berpengaruh positif dan signifikan terhadap minat beli pelanggan

H3. Promosi dan Store Interior berpengaruh positif dan signifikan terhadap minat beli pelanggan

\section{HASIL DAN PEMBAHASAN}

\section{a. Uji Validitas}

Tabel 1. Hasil Uji Validitas

\begin{tabular}{llll}
\hline & Corrected Item- Total Correlation & Cronbach's Alpha & If Item Deleted \\
\hline Promosi (X1) & 0.370 & 0.708 \\
Store Interior (X2) & 0.462 & 0.587 & \\
Minat Beli Pelanggan (Y) & 0.663 & 0.257 & \\
\hline
\end{tabular}

Dari hasil program SPSS versi 17, hasil perhitungan uji validitas terhadap kuesioner (Tabel 1) menunjukkan bahwa instrumen kuesioner semuanya valid karena merupakan nilai dari Corrected Item Total Correlation > dari r-tabel dengan r-tabel $=0,361$ dan semuanya lebih besar dari r-tabel sehingga kuesioner penelitian ini valid.

\section{b. Uji Reliabilitas}

Tabel 2. Hasil Uji Reliabilitas

\begin{tabular}{ll}
\hline Cronbach's Alpha & N of Items \\
\hline 0,641 & 25 \\
\hline
\end{tabular}

Dari hasil program SPSS versi 17, hasil uji reliabilitas terhadap kuesioner penelitian ini (Tabel 1) memperoleh koefisien reliabilitas (R) /Cronbach's Alphasebesar 0,641, dimana nilai tersebut lebih besar dari 0,500 sehingga dapat disimpulkan bahwa instrumen (responden) angket ini reliabel atau handal (Ghozali, 2002). Oleh karena itu instrumen kedua angket ini juga reliabel atau handal. 


\section{c. Uji Asumsi Klasik}

1. Uji Normalitas

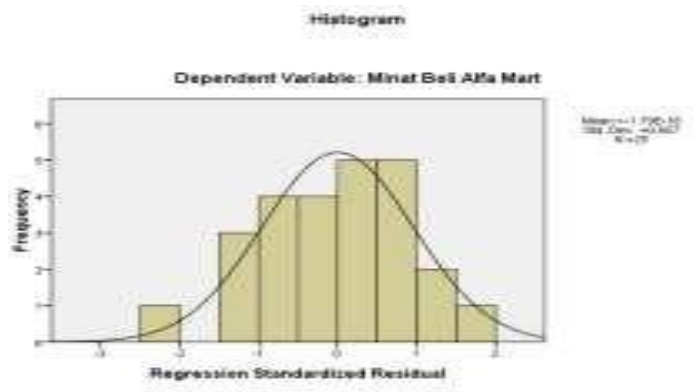

Gambar 1. Grafik Histogram disertai Kurva Normal

Dari Grafik diatas, dapat dilihat kemungkinan data terdistribusi dengan normal, dilihat dari sumbu 0 (nol) regresi. Hal ini dapat dipastikan terdistribusi dengan normal dengan melihat hasil uji Kolmogorov Smirnov Z di bawah ini

Tabel 3. Hasil Uji Normalitas

\begin{tabular}{clll}
\hline & Promosi & Store Interior & Minat Beli \\
\hline Asymp. Sig (2-tailed) & 0,229 & 0,116 & 0,521 \\
Ket & Normal & Normal & Normal \\
\hline
\end{tabular}

Berdasarkan hasil perhitungan pada tabel 3 di atas dapat diketahui nilai Asymptotic Significance adalah berada diatas nilai 0,05 yang berarti data terdistribusi dengan normal. Dari dua alat uji Normalitas yaitu Grafik Histogram dan Uji Statistik Kolmogorov-Smirnov Z, dapat disimpulkan bahwa data terdistribusi normal.

\section{Uji Multikolinearitas}

Tabel 4. Hasil Uji Multikolinearitas

\begin{tabular}{llll}
\hline Variabel & Tolerance & VIF & KET \\
\hline Promosi & 0.972 & 1.029 & Bebas Multikolinieritas \\
Store Interior & 0.972 & 1.029 & Bebas Multikolinieritas \\
\hline
\end{tabular}

Dari hasil perhitungan tabel 4 di atas diperoleh nilai VIF (Variance Inflation Factor) untuk setiap variabel bebas berada dibawah angka 10 atau nilai Tolerance diatas nilai $0,1(>0,1)$. Hal ini berarti bahwa tidak adag ejala Multikolinearitas antar variabel independent.

\section{Uji Liniearitas}

Hasil uji ini untuk mengetahui apakah terdapat hubungan antara variabel independent dan variabel dependent, dengan melihat nilai Significance-nya. Jika nilai tersebut $<0,05$; maka terdapat hubungan antara variabel independent dengan variabel dependent. Dari hasil program SPSS versi 20 didapat hasil sebagai berikut:

Tabel 5. Hasil Uji Linieritas

\begin{tabular}{lllll}
\hline Minat Beli (Y) Promosi (x1) & Mean Square & F & Sig & Ket \\
\hline Deviation From Liniearity & 0.296 & 1.918 & 0.110 & Linier \\
\hline
\end{tabular}

Dari hasil program SPSS versi 20 (tabel 5) ) hasil analisis menunjukkan bahwa harga F sebesar 1,918 dengan signifikansi 0,110 (di atas 0,05$)$. Karena nilai sig $>\alpha,(\alpha=0,05)$ sehingga dapat disimpulkan bahwa model regresi linear.

\section{Uji Heteroskesdastisitas}

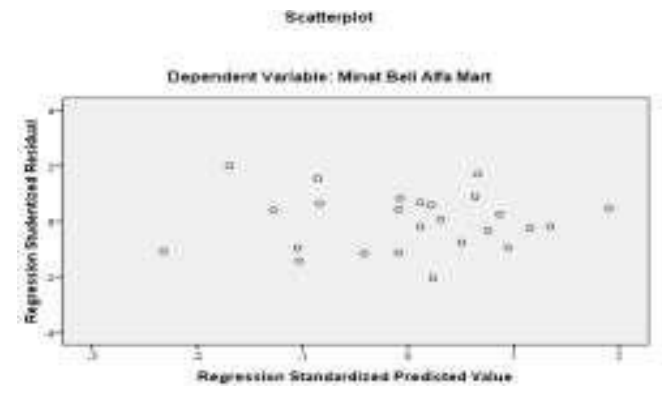

Gambar 2. Grafik Scatterplot 
Dari hasil gambar 2 diatas, dapat dilihat suatu kemungkinan tidak terjadinya Heteroskedastisitas karena dari grafik Scatterplot, dapat dilihat bahwa grafik tidak membentuk satu pola tertentu yang teratur (bergelombang, melebar kemudian menyempit) dan tidak ada pola yang jelas. Dapat disimpulkan secara keseluruhan tidak terjadi heteroskedastisitas dalam penelitian ini.

\section{Uji F}

Berdasarkan hasil pengujian secara serempak, maka diperoleh nilai Fhitung $=8,638$ dan Ftabel $=2,70$ karena memiliki nilai Fhitung $>$ Ftabel dan memiliki nilai sig atau value $=0,002$, karena nilai probabilitas yang lebih kecil dari nilai standar $(0,002<0,05)$, maka dapat disimpulkan bahwa variabel promosi dan storeinterior mempunyai pengaruh positif dan signifikan terhadap minat beli pelanggan.

\section{Koefisien Determinasi $\left(\mathbf{R}^{2}\right)$}

Berdasarkan hasil perhitungan uji determinasipada (tabel 6), maka dapat disimpulkan model regresi layak untuk digunakan karena pada tabel 6 diketahui nilai Adjusted $R$ Square $(R$ 2) bernilai 0,389 atau 38,9\%; berarti bahwa 38,9\% minat beli pelanggan Indomaret Johor dipengaruhi variabel independent. Sedangkan $61.1 \%$ dipengaruhi factor lain di luar model regresi

\section{Uji t}

Tabel 9. Hasil Uji t

\begin{tabular}{lllll}
\hline variable & $\mathrm{t}$ tabel $5 \%$ & $\mathrm{t}$ hitung & Sig & Ket \\
\hline promosi & 2.000 & 2.083 & 0.09 & H0 ditolak \\
Store Interior & 2.000 & 3.197 & 0.00 & H0 ditolak \\
\hline
\end{tabular}

Berdasarkan hasil perhitungan uji t (tabel 9) diatas diketahuivariabel promosi memiliki nilai thitung > ttabel $(2,083>2,000)$ dan nilai significance di bawah 0,05 atau $\mathrm{p}<0,05$ maka H0 ditolak dan H1 diterima. Variabel promosi berpengaruh positif dan signifikan terhadap minat beli.Artinya semakin tinggi promosi maka semakin tinggi minat beli pelanggan.Sebaliknya semakin rendah promosi maka semakin rendah minat beli pelanggan. Berdasarkan penelitian ini menunjukkan bahwa jika promosi ditingkatkan sebesar satu satuan maka minat beli pelanggan akan meningkat sebesar 0,412 satuan, faktor-faktor lain tetap dan jika variabel store interior ditingkatkan sebesar satu satuan maka minat beli pelanggan akan meningkat sebesar 0,380 satuan, faktor- faktor lain tetap. Berdasarkan hasil uji t menunjukkan bahwa variabel store interior memiliki nilai thitung $>\mathrm{t}$ tabel $(3,197>2,000)$ dan nilai significance di bawah 0,05 atau $\mathrm{p}<0,05$ maka H0 ditolak dan $\mathrm{H} 2$ diterima. Variabel store interior berpengaruh positif dan signifikan terhadap minat beli. Artinya semakin tinggi store interior maka semakin tinggi minat beli pelanggan. Sebaliknya semakin rendah store interior maka semakin rendah minat beli pelanggan.

\section{d. Teknik Analisa Data Regresi Linear Berganda}

Tabel 6. Hasil Regresi Berganda

\begin{tabular}{llll}
\hline & Koefisien & t hitung & sig \\
\hline Konstanta & 0.347 & & \\
Promosi & 0.412 & 2.083 & 0.049 \\
Store Interior & 0.380 & 3.197 & 0.004 \\
R2 & 0.389 & & \\
F Statistik & 8.638 & & \\
\hline
\end{tabular}

Adapun bentuk dari persamaan regresi berganda berdasarkan tabel di atas dapat dijabarkan melalui rumus regresi berganda sebagai berikut:

$Y=0,347+0,412 X_{1}+0,380 X_{2}$.

Penjelasan untuk persamaan regresi berganda

a. Nilai konstanta dalam regresi artinya jika perusahaan tidak menggunakan promosi dan store interior maka tidak akan ada pembelian. Karena pelanggan tertarik untuk berbelanja bukan hanya pada produk yang dijual tetapi dipengaruhi oleh promosi yang sering diberikan dan store interior nyaman, sehingga pelanggan akan merasakan adanya manfaat diperoleh dari promosi dan store interior.

b. Nilai koefisien regresi variabel promosi artinya bahwa pelanggan dapat merasakan manfaat dari promosi ketika pelanggan berkunjung ke Indomaret Apabila perusahaan dapat meningkatkan promosi maka jumlah pengunjung yang berbelanja di Indomaret akan meningkat karena minat beli pelanggan juga meningkat.

c. Nilai koefisien regresi variabel store interior artinya pelanggan dapat merasakan store interior yang ada pada Indomaret. Apabila perusahaan dapat mengelola store interior dengan lebih baik maka jumlah pengunjung yang akan berbelanja akan meningkat disebabkan minat beli pelanggan Indomaret meningkat.

d. Promosi dan store interior berpengaruh secara signifikan terhadap minat beli pelanggan. Pengelola dapat memprioritaskan dalam mengelola promosi dan store interior secara lebih efektif karena pelanggan lebih 
mengutamakan promosi dan store interior dalam melakukan pembelian. Dengan meningkatnya promosi dan store interior akan meningkatkan minat beli pelanggan dalam berbelanja di Indomaret

\section{KESIMPULAN}

Setelah melalui penelitian dapat disimpulkan promosi yang diberikan oleh Indomaret masuk kategori tinggi hal ini terlihat pada tabel 9. Indomaret dapat memberikan strategi untuk peningkatan jumlah promosi supaya dapat meningkatkan minat beli pelanggan yang berbelanja di Indomaret. Promosi penjualan yang diberikan tidak hanya promosi melalui personal selling melainkan ditambahkan dengan promosi melalui iklan di televisi atau melalui website. Store Interior yang diberikan oleh Indomaret termasuk kategori tinggi. Indomaret dapat meningkatkan minat beli pelanggan dengan cara memperbaiki store interior. Indomaret dapat meningkatkan kualitas store interior dengan cara memberikan kualitas interior yang baik dan menarik, seperti letak susunan produk, ruang yang menggunakan pendingin ruangan, musik dan cat dinding yang menarik. Minat beli pelanggan Indomaret termasuk kategori tinggi. Hal yang dapat meningkatkan minat beli pelanggan yaitu Indomaret dapat memberikan sesuatu yang berbeda dari perusahaan ritel lainnya .Indomaret dapat Memberikan promosi setiap hari dan desain interior yang unik dan nyaman sehingga pelanggan merasa puas saat berbelanja Indomaret. Penelitian ini sangat bermanfaat karena perusahaan dapat memprioritaskan pada promosi dan store interior, karena pelanggan tertarik berbelanja karena adanya promosi yang diberikan dan store interior yang diberikan perusahaan. Penelitian dengan judul promosi dan store interior dapat diterapkan pada perusahaan lain jika ingin meningkatkan minat beli pelanggan. Hal ini sangat penting agar perusahaan dapat bertahan dan dapat bersaing dengan perusahaan lain dalam menjalankan usahanya. Untuk penelitian selanjutnya apabila ada peneliti yang ingin meneliti tentang minat beli pelanggan sebaiknya menggunakan variabel lain selain variabel promosi dan store interior.

\section{DAFTAR PUSTAKA}

Alma, Buchari. (2007). Manajemen Pemasaran dan Pemasaran Jasa.Bandung:CV .Alfabeta.

Astrid Kusumowidagdo. (2010). "Pengaruh Desain Atmosfer Toko Terhadap Perilaku Belanja” Jurnal Manajemen Bisnis. Vol. 3 No. 1 April-Juli 2010 (17-32).

Berman, Barry \& Evans, Joel R. (2007)..Retail Management: A Strategic Approach (11th Ed.). New Jersey:Prentice Hall. Ghozali, Imam. (2002). Statistik Non Parametrik.Semarang: Badan Penerbit Universitas Diponegoro.

Kotler, Philip dan Amstrong. (2007).Marketing An Introduction.(Eight Edition). New Jersey: Prentice Hall.

Kotler, Philip dan Keller, Kevin Lane.(2007).Manajemen Pemasaran.Edisi 12 Jilid 1dan 2. Terjemahan: Benyamin Molan. Jakarta: PT. Indeks.

Kottler, Philip. (2007). ManajemePemasaran.Edisi ke sebelas.Jilid 2.Edisi Bahasa Indonesia. Jakarta:Penerbit Indeks.

Oliver, Richard L. (2008). Satisfaction: A. Behavioral Perspective on The Consumer. New York:McGraw- Hill.

Swastha,Banu dan Irawan. (2008). Manajemen Pemasaran Modern. Cetakan ke- 13. Yogyakarta:Liberti.

Schiffman, Leon G dan Kanuk, LeslieLazar.(2007). Consumer Behavior. ( $7^{\text {th }}$ ed) . New Jersey: Pearson Prentice Hall.

Tjiptono, Fandy.(2007). Strategi Pemasaran. Yogyakarta: Penerbit Andi offset

Utami, Widya Cristina. (2006). Manajemen Ritel. Jakarta: Salemba Empat. 